\title{
Analysis of the bullwhip effect with multi-echelon, multi-product supply chains
}

\author{
M. Ghaffari* and N. Javadian
}

Department of Industrial Engineering, Mazandaran University of Science and Technology, Babol, Iran

\section{H R O N I C L E}

\begin{tabular}{l}
\hline Article history: \\
Received March 162013 \\
Received in revised format \\
May 92013 \\
Accepted May 92013 \\
Available online \\
May 15 2013 \\
\hline Keywords: \\
Multi-echelon \\
Multi-product supply chain \\
Bullwhip \\
\hline
\end{tabular}

\section{A B S T R A C T}

\begin{abstract}
The bullwhip effect is a phenomenon in forecast-driven distribution channels, which is associated with a trend of larger and larger swings in inventory in response to changes in demand, as we look at firm further back in the supply chain for a particular product. This paper deals with the bullwhip effect in a multi-echelon multiple products supply chain with correlated market demands. The downstream retailer procures products from an un-capacitated upstream supplier to meet the correlated market demands of multiple products. This paper proposes a new method based on demand forecasting technique and uses a simple moving average to eliminate the bullwhip effect, which is proved to be effective under some circumstances.
\end{abstract}

\section{Introduction}

The bullwhip effect is a phenomenon in forecast-driven distribution channels, which is associated with a trend of larger and larger swings in inventory in response to changes in demand, as we look at firm further back in the supply chain for a particular product. To demonstrates bullwhip effects, consider a case study depicted in Fig. 1 where a general supply chain, consists of three various levels of enterprises (Chen \& Lee 2004). According to Fig. 1, the first level enterprise is retailer or market where the products are sold to customer under the conditions subject to a given lower bound of customer service. The second level enterprise is a distribution center (DC) or warehouse using various types of transportation capacity to deliver products from plant side to retailer side. Finally, the third level enterprise is plant or manufacturer where it produces one product each period. The fixed manufacture/idle costs are also employed: on one side, if the production line is changed over to manufacture another product, manufacture cost remains fixed; on the other side, if the production line is set up to manufacture one specific product but actually is idle and the idle cost is also fixed. Furthermore, the plant has options of manufacturing in regular time or overtime to satisfy the customer

* Corresponding author. Tel: +98 9123386958

E-mail: Ghaffari@ustmb.ac.ir (M. Ghaffari)

(C) 2013 Growing Science Ltd. All rights reserved. doi: $10.5267 / \mathrm{j} . \mathrm{ijiec} .2013 .05 .002$ 
demand. To simplify the problem here, we do not consider the problem of purchase and inventory of the raw material in plants nor do we incorporate the purchasing cost into manufacturing cost.

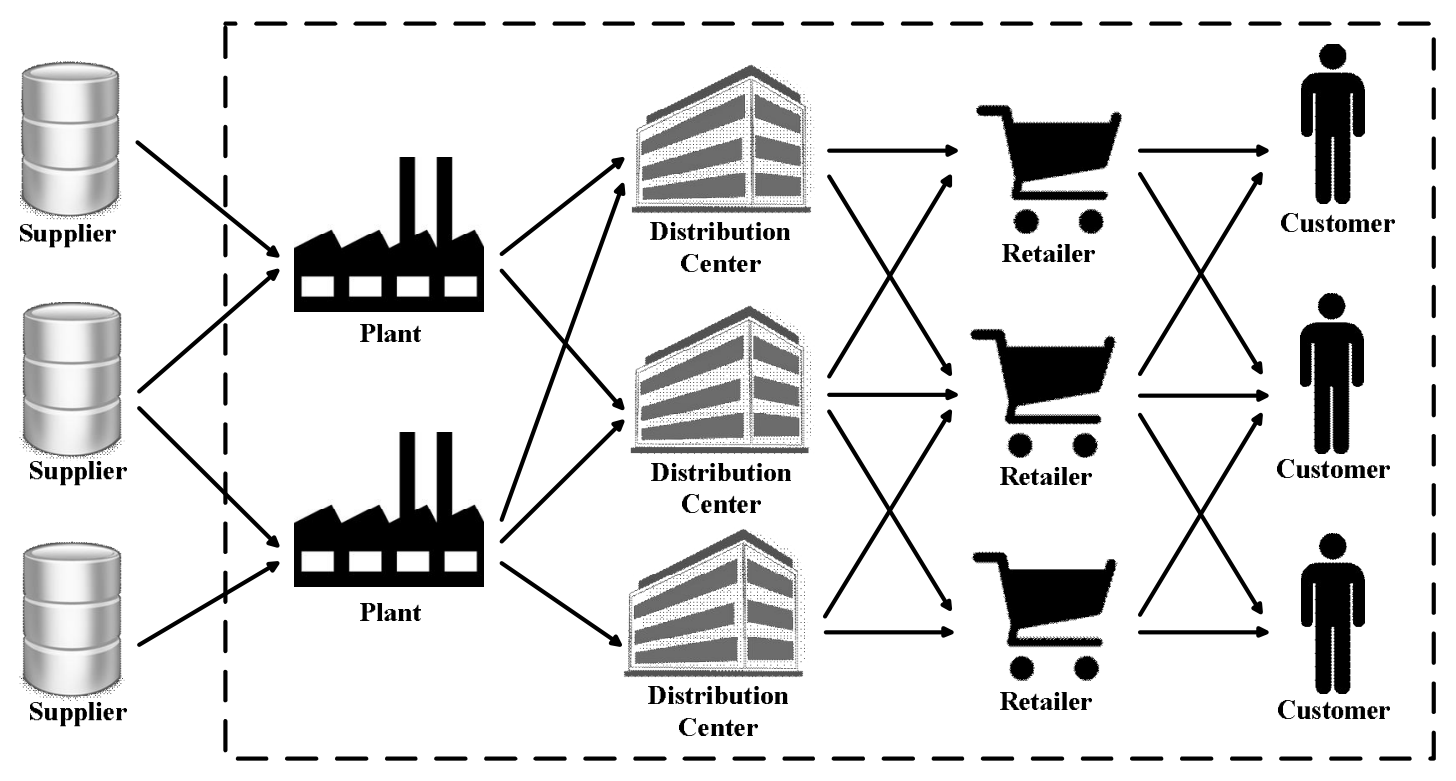

Fig. 1. Research region

The bullwhip effect is a phenomenon in the process of the supply chains and it happens when demand fluctuation increases from downstream retailers are passed to upstream suppliers. Procter \& Gamble found that "Diapers" supply chain, the fluctuations in the amount of the distribution center order to be greater than the market sales (Lee et al., 1996). Demand increases variability of excess raw materials or product sourcing and capacity investment, inventory costs and transportation costs increase from $12.5 \%$ to $25 \%$ of total costs of products (Kurt Salmon Associates, 1993). High variability causes congestion of the system and the extension of the production cycle, seriously affect the service level. To meet the needs of various customer groups and to enhance competitiveness, companies are often at the same time production or sale of a variety of related products. In a multi-product demand environment, the bullwhip effect exists and when it happens, how to weaken the bullwhip effect business operations management needs special attention.

In terms of operational management perspective, the bullwhip effect includes demand signal processing, inventory rationing, order quantity and price fluctuations (Lee et al., 1997). Chen et al. (2000a) proved that we may face a single product supply chain bullwhip effect given the quantitative expression of the bullwhip effect, and information sharing can weaken but not effectively eliminate the bullwhip effect (Chen, 1998). Effects of deterministic and stochastic order lead times on bullwhip effect in supply chains have been well conducted (Chen, 2000b; Lee et al., 2000; Zhang, 2004; Luong, 2007; Chatfield et al., 2004). Most of the research papers showed that the reduction on lead-time variation could reduce the bullwhip effect. There are some major contributions on this paper. First, the bullwhip effect in a two-stage supply chain with one supplier and two retailers is quantified. After that, the bullwhip effect's behaviors will be investigated with stochastic order lead-time and stochastic demand. Finally, a mathematical condition on which bullwhip effect measures in the supply chain is developed.

This article discusses downstream retailers and upstream suppliers, the existence of the bullwhip effect, quantified and weakened. The main difference between this paper and previous studies is to consider a multi-product (Products are independent to each other) market demand autocorrelation and cross bullwhip effect. The proposed study uses simple moving average method for demand forecasting, multi-product supply chain in the proof of the existence of the bullwhip effect and quantitative 
expression for further elimination of the bullwhip effect in the supply chain, effective under certain conditions and demand forecasting method.

This paper considers downstream retailers for more than two products in the supply chain, from upstream suppliers with $m$ kinds of products to meet the uncertain market demand. We assume that demand is insufficient for the next period and there are $m$ kinds of products to meet the market demand, retailers observe their own inventory levels at the end of period $t$ for the supplier orders $Q_{i t}(i \in I, I=$ $\{1, \ldots, m\})$. The suppliers ship $m$ kinds of products to the retailer. Orders issued by the retailer at the end of $t$ and the beginning of the period received $t+L(L \geq 1)$, and all products have the same fixed order lead time $L-1$ so that order lead time is zero, retailer $t$ the end of orders, receives in the beginning of $t+1$ product and $D_{i t}(i \in I)$ is the market demand for $\mathrm{i}^{\text {th }}$ product at time $\mathrm{t}$.

Multi-product supply chain market demand happens for different reasons. It may happen when there are different stages for the same market, it may be associated with market demand for different products at the same period. Different products associated with market demand such as meat products, pork, beef, chicken, etc. The market needs to meet the following two assumptions.

1) The expectations of the market demand have nothing to do with the period $E\left(D_{i t}\right)=\mu_{i}, i \in I, t \in Z$, $E\left(D_{i t}\right)$ independent in the period;

2) market demand for the co-variance with the period has nothing to do only with the period of poor demand for $t+\tau$ period of product $i(i \in I)$ demand $D_{i, t+\tau}$ and $t$ period of product $k(k \in I)$ demand $D_{k t}$ the co-variance $\gamma_{i k}^{\tau}=\operatorname{Cov}\left(D_{i, t+\tau}, D_{k t}\right)$ with a specific period of time $t$ independent only related to the period difference $\tau$ i.e. $\gamma_{i k}^{\tau}=\operatorname{Cov}\left(D_{i, t+\tau}, D_{k t}\right)$ is only a function of $\tau$.

The first assumption shows the same expectations of the various stages of the same product demand and the second assumption shows that demand for the same product in different stages changes with $\gamma_{i k}^{0}=\operatorname{Cov}\left(D_{i, t}, D_{k t}\right)$.

\section{Demand forecasting and inventory strategies}

Consider a retailer $p\left(p \in Z^{+}\right)$where demand is forecasted based on a simple moving average technique and $\widehat{D_{l t}}$ represents demand for product $i$ at time $t$.

$\widehat{D_{l t}}=\frac{D_{i, t-1}+D_{i, t-2}+\cdots+D_{i, t-p}}{p}$.

The single retailer ordering strategy is a basic inventory strategy (Lee, 1997) (base inventory policy) set to the level of inventory of product (order-up-to level) $y_{i t}$ by demand forecasting:

$y_{i t}=L \widehat{D}_{l t}+z_{i} \widehat{\sigma_{l t}}, \forall i \in I$,

where $L \widehat{D}_{l t}$ is the estimate for lead time of product $i$ at time $t$, , $\widehat{\sigma_{l t}}$ is standard deviation for demand of product $i$ at period $t$ and $z_{i}$ corresponds to the service level of the retailer of the product $i$.

Lee et al. (1997) pointed out that the market demand forecast error standard deviation and the standard deviation of demand during lead time were positively correlated. Therefore, $\widehat{\sigma_{l t}}$ has nothing to do with the period and can be considered as an arbitrary value. Based on the above analysis we can directly obtain orders issued by retailers to suppliers $i$ order $Q_{i t}$ for: 
$Q_{i t}=y_{i t}-y_{i, t-1}+D_{i, t-1}=\left(1+\frac{L}{p}\right) D_{i, t-1}-\frac{L}{p} D_{i, t-p-1}$

Note that $Q_{i t}$ may be negative, actual orders $t$ should be $\max \left(Q_{i t}, 0\right)$ for discussion, here we assume that excess inventory does not cost us for return to the suppliers, where $Q_{i t}$ desirability of negative.

\section{Bullwhip effect in a multi-product supply chain}

Consider a firm in terms of a weighted comprehensive survey of multi-product demand variability, product weight vector:

$w=\left(w_{1}, \ldots, w_{m}\right), \sum_{i=1}^{m} w_{i}=1, w_{i} \geq 0,1 \leq i \leq m$

Therefore, the variations on order quantity $\left(Q_{t}\right)$ to demand $\left(D_{t}\right)$ at time $t$ is defined as follows,

$\operatorname{VR} R_{t}=\frac{\operatorname{Var}\left(Q_{t}\right)}{\operatorname{Var}\left(D_{t}\right)}=\frac{\operatorname{Var}\left(\sum_{i=1}^{m} w_{i} Q_{i t}\right)}{\operatorname{Var}\left(\sum_{i=1}^{m} w_{i} D_{i t}\right)}$

When $V R_{t} \geq 1$ this means that changes on order quantity was bigger than changes on demand and the supply chain in the period $t$ suffers from bullwhip effect. In addition, due to the market demand of products, we have the same expectations and variances of weighted total demand received by the retailers, suppliers also have the same expectations, and variance variation ratio has nothing to do with the period.

Consider $t$ weighted total market demand $D_{t}$ for the first $t+p$ periods of market weighted demand and let $\rho_{p}$ be the correlation coefficient for $D_{t+p}$. Now we may consider the following proposition.

Proposition 1: multi-product supply chain variability ratio has no relationship with period, for any t:

$V R_{t}=1+\left(\frac{2 L}{p}+\frac{2 L^{2}}{p^{2}}\right)\left(1-\rho_{p}\right)$

Proof:

The proof is straightforward and can be completed using Eqs. (1-3) to have the following,

$Q_{i t}=\left(1+\frac{L}{p}\right) D_{i, t-p}-\frac{L}{p} D_{i, t-p-1}, \forall i \in I$,

$Q_{t}=\sum_{i=1}^{m} w_{i} Q_{i t}=\left(1+\frac{L}{p}\right) \sum_{i=1}^{m} w_{i} D_{i, t-1}-\frac{L}{p} \sum_{i=1}^{m} w_{i} D_{i, t-p-1}=\left(1+\frac{L}{p}\right) D_{t-1}-\frac{L}{p} D_{t-p-1}$.

Now we calculate $t$ retailer demand weighted total variance as follows,

$\operatorname{Var}\left(Q_{t}\right)=\operatorname{Var}\left[\left(1+\frac{L}{p}\right) D_{t-1}-\frac{L}{p} D_{t-p-1}\right]=\left(1+\frac{2 L}{p}+\frac{2 L^{2}}{p^{2}}\right) \sigma^{2}-2 \frac{L}{p}\left(1+\frac{L}{p}\right) \rho_{p} \sigma^{2}$.

Therefore, the $t$ variability ratio is as follows,

$V R_{t}=1+\left(\frac{2 L}{p}+\frac{2 L^{2}}{p^{2}}\right)\left(1-\rho_{p}\right)$

According to Proposition 1, the variation of the ratio of the multi-product supply chain is determined by order lead time, the joint decision of the weighted total number of periods of demand forecasting and 
market demand. The results are similar to the results of Lee et al. (1997) but we need to pay attention that the correlation coefficient $\rho_{p}$ is a comprehensive reflection of the multi-product market demand correlation.

Proposition 2: Regardless of the number of periods, simple moving average forecasts how to choose the bullwhip effect in the supply chain.

\section{Proof:}

Note that, in extreme cases $\rho_{p}=1$ (this time $V R_{t}=1$ ), since the expectation and variance are equal to the weighted market demand, the complete positive correlation to the weighted market demand for products inevitably requires $p$ equal periods, completely.

\section{Bullwhip effect weakened method}

Through the analysis of the previous section, the bullwhip effect in supply chain are associated with three factors: market demand for the correlation coefficient of the weighted, total order lead time and simple moving average forecast the number of periods (hereinafter referred to as the predicted number of installments). Thus diminishing bullwhip effect in addition to reduce the lead time period, increases the demand forecast smoothness, attention should also be paid to retailers receiving demand-weighted total correlation.

\subsection{Weakening demand forecast}

To present the implementation of the proposed method based on the demand forecast and the elimination of the bullwhip effect in the supply chain, we may consider retailers for any products $i \epsilon I$ in the form of forecast demand (referred to as the interval demand substitution law):

$\widehat{D_{l t}}=D_{i, t-p}$,

where $p$ is the period interval parameter. Prediction method based on Eq. (10) is actually a special weighted moving average forecast, and $E\left(\widehat{D_{l t}}\right)=\mu_{i}$, so this demand forecasting method is feasible.

According to the Eq. (2) and the Eq. (3) we have,

$Q_{t}=L D_{t-p}-L D_{t-p-1}+D_{t-1}$

Therefore, for any $t$, the interval demand alternative method variance ratio is as follows,

$V R_{t}^{\prime}=1+2 L\left[\left(1-\rho_{1}\right) L+\left(\rho_{p-1}-\rho_{p}\right)\right]$.

If there is $p$, so

$L<\frac{\left(\rho_{p}-\rho_{p-1}\right)}{\left(1-\rho_{1}\right)}$

That $\left(1-\rho_{1}\right) L+\left(\rho_{p-1}-\rho_{p}\right)<0$ now $V R_{t}^{\prime}<1$ bullwhip effect is effectively eliminated.

The above results show that when retailers choose the interval demand for alternative method to forecast demand in the supply chain, bullwhip effect does not occur, where period interval parameter $p$ satisfies $L<\left(\rho_{p}-\rho_{p-1}\right) /\left(1-\rho_{1}\right)$. 


\subsection{Example}

For Eq. (6) when multi-product market demand correlation $\rho_{p}=0$, we have

$V R_{t} \geq 1+\left(\frac{2 L}{p}+\frac{2 L^{2}}{p^{2}}\right)$

Let $L$ be equal to $1,3,5$ when we calculate $V R_{t}$, with the values of different forecast sample $p$ the values of bullwhip effect are shown in Table 1:

Table 1

The value of the bullwhip effect by calculating forecast sample value of $p$

\begin{tabular}{cccc}
\hline & & Value of $V R_{t}$ & \\
& $\mathrm{~L}=1$ & $\mathrm{~L}=3$ & $\mathrm{~L}=5$ \\
\hline 1 & 5.000 & 25.000 & 61.000 \\
2 & 2.500 & 8.500 & 18.500 \\
3 & 1.889 & 5.000 & 9.889 \\
4 & 1.625 & 3.625 & 6.625 \\
5 & 1.480 & 2.920 & 5.000 \\
6 & 1.389 & 2.500 & 4.056 \\
7 & 1.327 & 2.224 & 3.449 \\
8 & 1.281 & 2.031 & 3.031 \\
9 & 1.247 & 1.889 & 2.728 \\
\hline 10 & 1.220 & 1.780 & 2.500 \\
\hline
\end{tabular}

The bullwhip effect forecast sample $p$ relationship is shown in Fig. 1 .

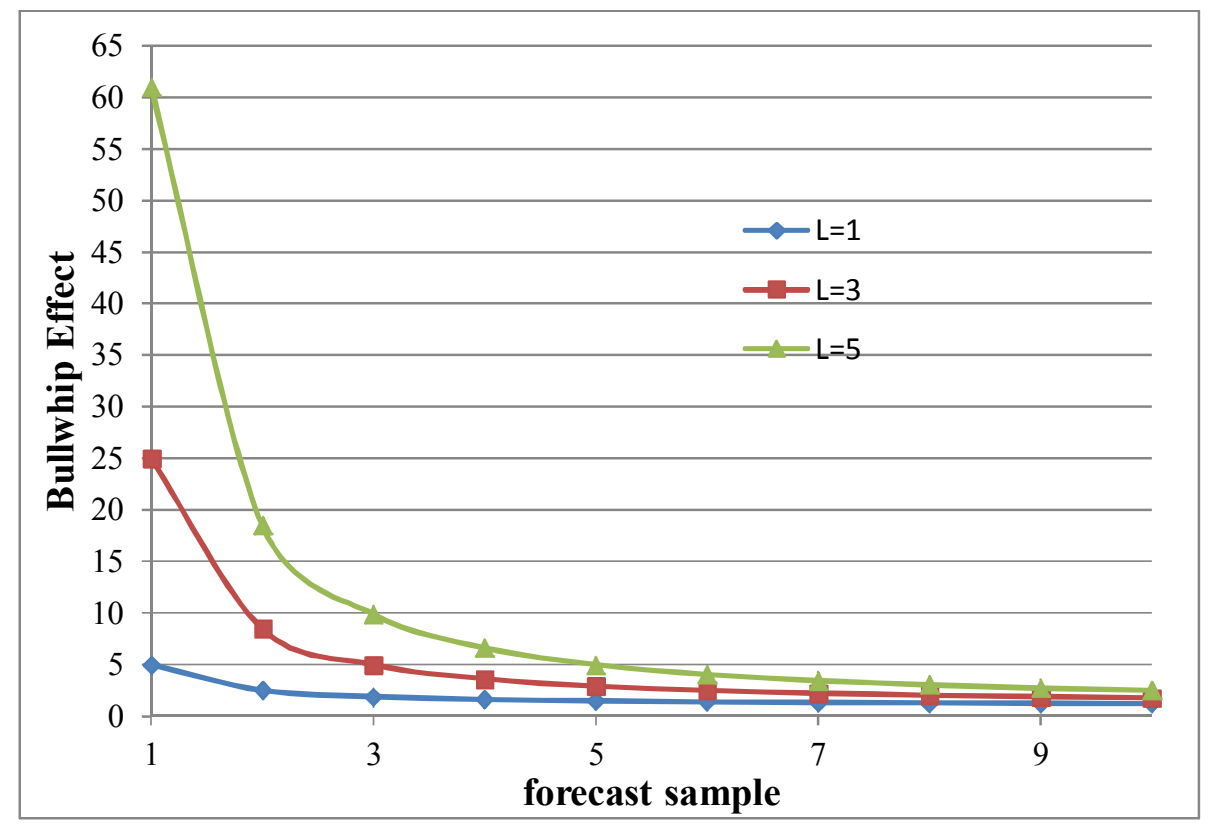

Fig. 1. Forecast sample $p$

According to the results of Table 1 and Fig. 1, as forecast sample $p$ increases we see a decrease on bullwhip effect. In other words, no matter what value is chosen for $L$, the results for bullwhip tend to the same limit. 
We may test seasonal changes in market demand for most of the products in real life by using sine and cosine curve fitting. Assuming the period $t, i$ market demand for $D_{i t}=\mu_{i}+A_{i} \cos (t)+B_{i} \sin (t)$, Among $E\left(A_{i}\right)=E\left(B_{i}\right)=0, \operatorname{Var}\left(A_{i}\right)=\operatorname{Var}\left(A_{i}\right)=\sigma_{i}^{2}$. The correlation coefficient between $A_{i}$ and $A_{k}$, $B_{i}$ and $B_{k}$ are the same as correlation coefficients between $A_{i}$ and $B_{k}$ independent $\forall i, k \in I$.

Suppose we have $\rho_{p}=\cos (p)$, therefore a simple moving average for the variation ratio is as follows,

$V R_{t}=1+\left(\frac{2 L}{p}+\frac{2 L^{2}}{p^{2}}\right)(1-\cos (p))$

Eq. (15) is based on a simple moving average bullwhip effect and whenever the lead time increases, forecast experiences cyclical changes.

According to Eq. (7):

$\frac{\rho_{p}-\rho_{p-1}}{1-\rho_{1}}=\frac{\cos (p)-\cos (p-1)}{1-\cos (1)}=\frac{2 \sin (p-0.5) \sin (0.5)}{\cos (1)-1} \approx-2.086 \sin (p-0.5)$

When $\mathrm{L}=1$, and $\mathrm{p}=5$, therefor $V R_{t}^{\prime} \approx 0.045$, the bullwhip effect did not occur; When $\mathrm{L}=2$, take $\mathrm{p}=$ 5 , the $V R_{t}^{\prime} \approx 0.928$, the bullwhip effect did not occur; When $\mathrm{L}>2$, there is no $p$ and makes the bullwhip effect $V R_{t}^{\prime}<1$. The results show that, when the correlation coefficient of the weighted total market demand meet certain conditions, the interval demand alternative method can effectively eliminate the bullwhip effect.

\section{Conclusion}

This article discussed the multi-product demand environment, suppliers and retailers with more than two products in the supply chain bullwhip effect. Findings have shown that using a simple moving average forecast demand for smooth product market demand, retailers bullwhip effect in a multiproduct supply chain is inevitable. We have discussed that it is possible to reduce the burden of bullwhip effect on supply chain management as long as some conditions hold.

\section{References}

Chaharsooghi, S. K., \& Heydari, J. (2010). LT variance or LT mean reduction in supply chain management: Which one has a higher impact on SC performance?. International Journal of Production Economics, 124(2), 475-481.

Chatfield, D. C., Kim, J. G., Harrison, T. P., \& Hayya, J. C. (2004). The bullwhip effect—impact of stochastic lead time, information quality, and information sharing: a simulation study. Production and Operations Management, 13(4), 340-353.

Chen, F. (1998). Echelon reorder points, installation reorder points, and the value of centralized demand information. Management Science, 44(12-Part-2), S221-S234.

Chen, F., Ryan, J. K., \& Simchi-Levi, D. (2000a). The impact of exponential smoothing forecasts on the bullwhip effect. Naval Research Logistics, 47(4), 269-286.

Chen, F., Drezner, Z., Ryan, J. K., \& Simchi-Levi, D. (2000b). Quantifying the bullwhip effect in a simple supply chain: The impact of forecasting, lead times, and information. Management science, 46(3), 436-443.

Chen, C. L., \& Lee, W. C. (2004). Multi-objective optimization of multi-echelon supply chain networks with uncertain product demands and prices. Computers \& Chemical Engineering, 28(6), 1131-1144. 
Dehbari, S., Pourrousta, A., Nezhad, S., Tavakkoli-Moghaddam, R., \& Javanshir, H. (2012). A new supply chain management method with one-way time window: A hybrid PSO-SA approach. International Journal of Industrial Engineering Computations, 3(2), 241-252.

Duc, T. T. H., Luong, H. T., \& Kim, Y. D. (2008). A measure of the bullwhip effect in supply chains with stochastic lead time. The International Journal of Advanced Manufacturing Technology, 38(1112), 1201-1212.

Fioriolli, J. C., \& Fogliatto, F. S. (2008, December). A Model to quantify the Bullwhip Effect in systems with stochastic demand and lead time. In Industrial Engineering and Engineering Management, 2008. IEEM 2008. IEEE International Conference on (pp. 1098-1102). IEEE.

Graves, S. C. (1999). A single-item inventory model for a nonstationary demand process. Manufacturing \& Service Operations Management, 1(1), 50-61.

Lee, H. L., Padmanabhan, V., \& Whang, S. (1997). Information distortion in a supply chain: the bullwhip effect. Management science, 43(4), 546-558.

Lee, H. L., So, K. C., \& Tang, C. S. (2000). The value of information sharing in a two-level supply chain. Management science, 46(5), 626-643.

Luong, H. T. (2007). Measure of bullwhip effect in supply chains with autoregressive demand process. European Journal of Operational Research,180(3), 1086-1097.

Kurt Salmon Associates. (1993). Efficient Consumer Response: Enhancing consumer value in the grocery industry. Research Department, Food Marketing Institute.

Zhang, X. (2004). The impact of forecasting methods on the bullwhip effect.International Journal of Production Economics, 88(1), 15-27. 